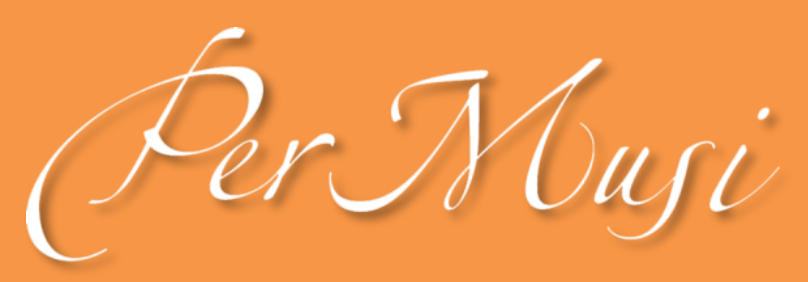

eISSN 2317-6377

\title{
Procedimentos Estruturais na Peça A Twilight's Song de Matthias Pintscher
}

\author{
Levy Oliveira \\ https://orcid.org/0000-0003-0634-0762 \\ Universidade Federal de Minas Gerais (UFMG) \\ pacheco.levy@gmail.com
}

João Pedro Oliveira

https://orcid.org/0000-0002-2222-3884

University of California at Santa Barbara (UCSB)

ippo@ucsb.edu

SCIENTIFIC ARTICLE

Submited date: 26 aug 2019

Final approval date: 28 oct 2020

Resumo: Este trabalho visa analisar os procedimentos estruturais da peça A Twilight's Song do compositor alemão Matthias Pintscher. A análise terá enfoque em três aspectos: desenvolvimento motívico, articulação global da forma e exploração tímbrica. Utilizando como referência bibliográfica textos de Steve McAdams, Kaija Saariaho, Panayiotis Kokoras e o filme A Lesson by Pierre Boulez, almeja-se descobrir quais técnicas foram utilizadas pelo compositor para alcançar a plenitude formal da obra.

Palavras-chave: Análise estrutural; Exploração tímbrica; Desenvolvimento motívico.

\section{TITLE: STRUCTURAL PROCEDURES IN THE PIECE A TWILIGHT'S SONG BY MATTHIAS PINTSCHER}

Abstract: This paper proposes to analyze structural aspects of the piece A Twlilight's Song by German composer Matthias Pintscher. The analysis will address three main aspects: motivic development, articulation of the global form and timbre exploration. Using as reference the film A Lesson by Pierre Boulez and texts by Steve McAdams, Kaija Saariaho and Panayiotis Kokoras, we aim to discover which techniques were used to achieve the overall form of the work.

Keywords: Structural analysis; Timbre exploration; Motivic development. 


\section{Procedimentos Estruturais na Peça A Twilight's Song de Matthias Pintscher ${ }^{1}$}

Levy Oliveira, Universidade Federal de Minas Gerais, pacheco.levy@gmail.com João Pedro Oliveira, University of California at Santa Barbara, jppo@ucsb.edu

\section{Introdução}

A Twilight's Song, composta em 1997, é uma das principais peças do catálogo do compositor alemão Matthias Pintscher. O orgânico instrumental consiste em soprano, harpa, piano, percussão, flauta baixo, clarone, viola e violoncelo. Durante a peça, a soprano canta (e declama) o poema The Hours Rise Up Putting Off Stars do escritor americano e. e. cummings. Na nossa análise, busca-se compreender como ocorrem as articulações formais da obra e quais foram as técnicas utilizadas pelo compositor para alcançar esse resultado. Este estudo propõe alcançar um maior entendimento do contexto atual da criação musical, estimulando uma constante atualização do nosso trabalho de composição e sua inserção no panorama dos nossos dias.

Durante o processo analítico realizado, a escuta foi um dos fatores de maior relevância. A nossa perspectiva sobre um trabalho essencialmente analítico, direciona-se para a valorização de características que possam ser auditivamente apreendidas por quem escuta a obra. Como destacado por McAdams e Saariaho (1985, 367), “No século XX, muitos experimentos mostraram que a estruturação, por si só, não é o suficiente, caso a mesma não possa ser compreendida ou decodificada por diversas razões". A partir da valorização da escuta, propõe-se hierarquizar padrões presentes na partitura, que possuam representatividade no resultado sonoro final, ou que ultrapassem aspetos composicionais importantes apenas para o compositor (por exemplo, metafísicos ou extramusicais), que não exercem necessariamente uma influência direta na estruturação global da peça.

\section{Desenvolvimento motívico}

Sendo esta obra baseada num poema, naturalmente, podemos supor que suas estruturas estão intrinsecamente ligadas. Tal pressuposto foi-nos confirmado pela audição da obra. Portanto, torna-se importante analisar, inicialmente, a estrutura do poema (figura 1).

\footnotetext{
${ }^{1}$ Este trabalho foi realizado com o apoio da CAPES, no âmbito do programa de pós-graduação da UFMG, na linha de pesquisa em Processos Analíticos e Criativos, sob a orientação do professor João Pedro Oliveira. Está inserido no projeto "Construção de Interfaces para Espacialização Sonora 3D e sua Aplicação na Composição" financiado pelo CNPq - Processo: 446978/2014-0.
} 


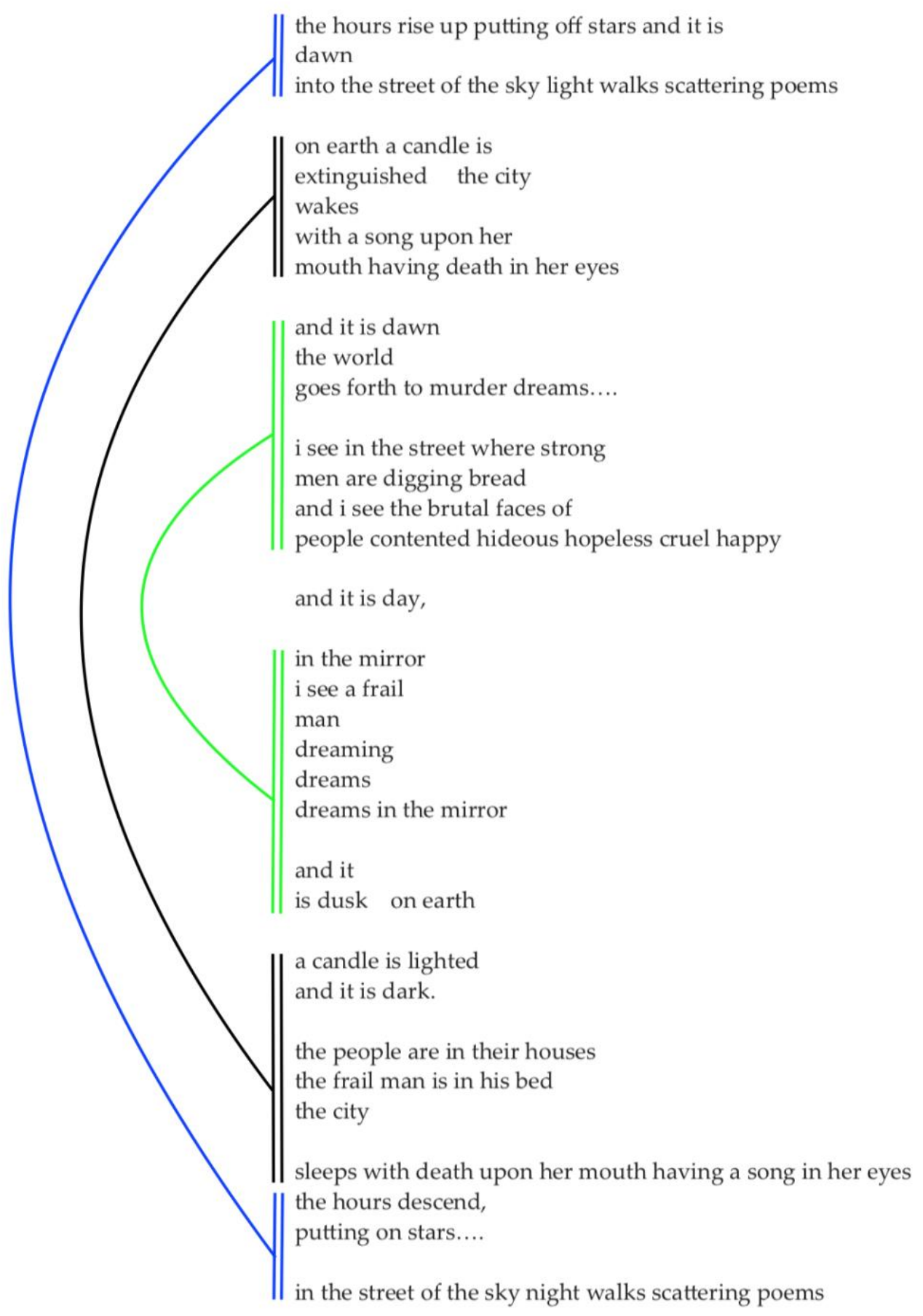

Figura 1 - Poema The Hours Rise Up Putting Off Stars de e. e. cummings

O poema narra acontecimentos do dia a dia de uma cidade, associando essa proposta narrativa a uma forma literária cíclica, onde frases se repetem com conteúdos linguísticos similares, mas, muitas vezes, com sentidos opostos. Essas semelhanças estão dispostas de uma forma espelhada, onde a frase "and it is day" é o eixo central. Sendo assim, os primeiros versos do poema são similares aos últimos (marcado em azul na figura 1), a segunda estrofe possui semelhanças com as penúltimas (marcado em preto) e a terceira e quarta estrofe são similares à quinta e sexta (marcado em verde). Como veremos mais a frente, essa estrutura é a mesma encontrada na peça do Matthias Pintscher. 
Essas semelhanças textuais influenciam a manipulação motívica realizada pelo compositor, usando com frequência um processo de text-painting, ou seja, a música reflete metaforicamente o significado literal do texto. As frases "...the city wakes with a song upon her mouth..." e "...the city sleeps with death upon her mouth..." (figura 2) exemplificam bem esse processo. Ao comparar o contorno melódico dessas duas frases é perceptível que ocorre na música o mesmo jogo de semelhança e oposição do texto. Logo no inicio de ambas as frases ("...the city wakes..." e "...the city sleeps..."), Pintscher utiliza as mesmas notas (a única exceção é a terceira nota - sendo mi bequadro na primeira frase e mi bemol na segunda), entretanto, os registros e a direcionalidade são diferentes. A diferenciação das oitavas permite que o gesto musical utilizado na parte do texto referente à cidade que acorda (movimento ascendente representando o ato de se levantar) seja oposto ao momento em que ela dorme (movimento descendente representando o ato de se deitar).

\section{38 - 42}

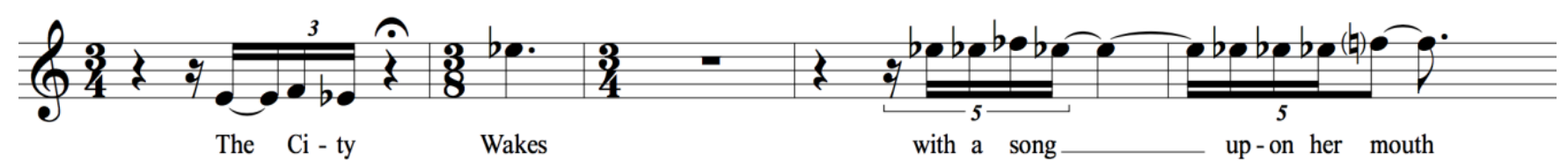

\section{108 - 112}

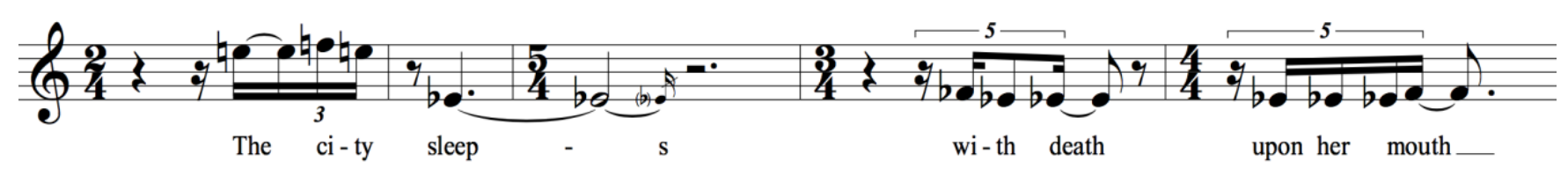

Figura 2 - Comparação entre padrões textuais e melódicos em A Twilight's Song

A mesma ideia é utilizada para terminar as frases "...with a song upon her mouth..." e "...with death upon her mouth...". Quando a cidade se encontra com uma música em sua boca, a melodia vocal projeta-se no registro agudo, com um timbre brilhante, referenciando a leveza desse momento. Por oposição, quando a sugestão textual possui uma certa morbidez, a melodia encontra-se no registro grave com um timbre mais opaco. Novamente, apesar das mudanças de registro, os conteúdos melódico e harmônico são idênticos.

O mesmo tipo de processo pode ser encontrado em outros pontos da obra. Nos c. 18-21 e 120-123, existem trechos que compartilham características textuais comuns, apesar do significado semântico ser antagônico. Nas frases "the hours rise up putting off stars" e "the hours descend putting on stars" (Figura 3) também é possível encontrar influências do texto na manipulação motívica. Apesar de existir uma diferenciação harmônica entre essas duas frases, as semelhanças ainda são muitas. Em "rise up" e "descend", o contorno melódico é mantido ficando uma terça menor mais grave quando o texto sugere o movimento de descida. Da mesma forma, as palavras "putting off" e "putting on" direcionam a melodia em sentidos diferentes para colorir a palavra "stars", sendo o registro novamente importante para essa representação. Quando as estrelas estão sendo 'tiradas' do céu, o registro utilizado é a região médiograve. Quando as estrelas estão sendo colocadas, é empregada a região vocal mais brilhante. 


\section{18-21}

$\mathrm{S}$

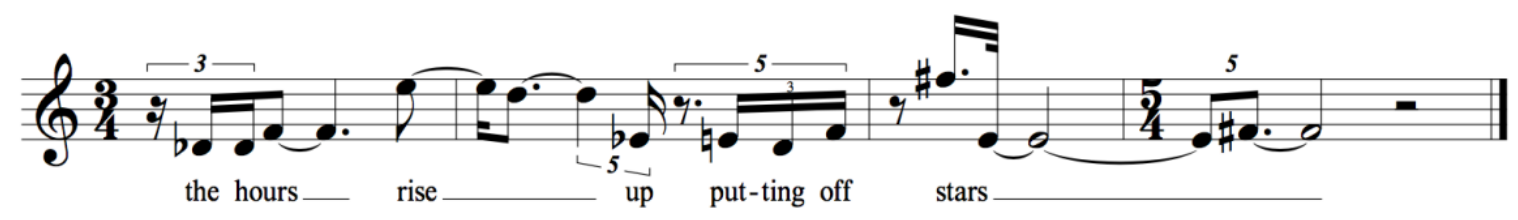

C. 120-123

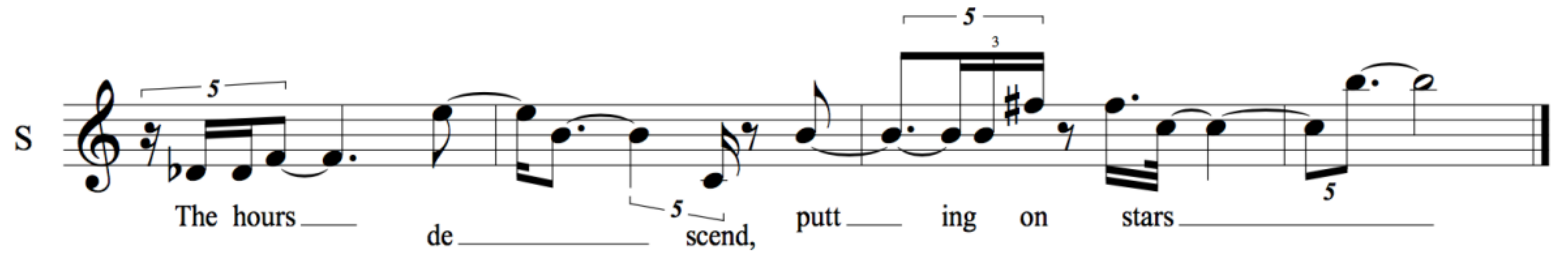

Figura 3 - Comparação entre padrões textuais e melódicos em A Twilight's Song.

Estas repetições variadas são em grande parte responsáveis pelo entendimento da forma global da obra, pois acontecem na voz solista, tornando-se mais evidentes e memoráveis para os ouvintes, fator relevante no processo de articulação formal. A importância da memória no processo de consolidação formal é ressaltada por McAdams e Saariaho (1985, 367): “Uma importante característica da forma musical é que ela se acumula na memória ao decorrer do tempo. Isso implica que, se algum elemento é facilmente relembrado, seu potencial de contribuição para a forma é maior que de outro elemento difícil de ser lembrado". Desta forma, pode-se afirmar que a forma da peça de Matthias Pintscher reflete a forma cíclica do poema de e. e. cummings (figura 1 ).

$\mathrm{Na}$ figura 4, encontra-se um gráfico que esquematiza a forma global da peça. $A$ Twilight's Song encontra-se dividida em introdução e 3 seções principais. As seções $A$ (c. 18-60) e $A^{\prime}$ (c. 86-135) apresentam similaridades e ambas podem ser divididas em três subseções. A subseção I (c. 18-34) de $A$ possui semelhanças com a subseção III de $A^{\prime}$ (c. 120-135), enquanto a subseção II (c. 34-48) de $A$ possui semelhanças com a subseção II (c. 95-120) de $A^{\prime}$ e a subseção III de A (c. 48-60) com a I de A' (c. 86-95). Ou seja, tal qual o poema de e. e. cummings (figura 1), a estrutura de A Twilight's Song também é espelhada e utiliza a seção B como eixo central deste espelhamento. Esta seção central é bastante contrastante em relação às demais, sendo assim, dedicaremos uma seção deste texto para analisá-la separadamente. 0 Motivo Inicial (MI) que apresentamos no gráfico será explicado mais adiante. A partir dessa divisão, buscou-se entender que procedimentos foram realizados por Pintscher para salientar e otimizar as articulações formais em sua obra. 


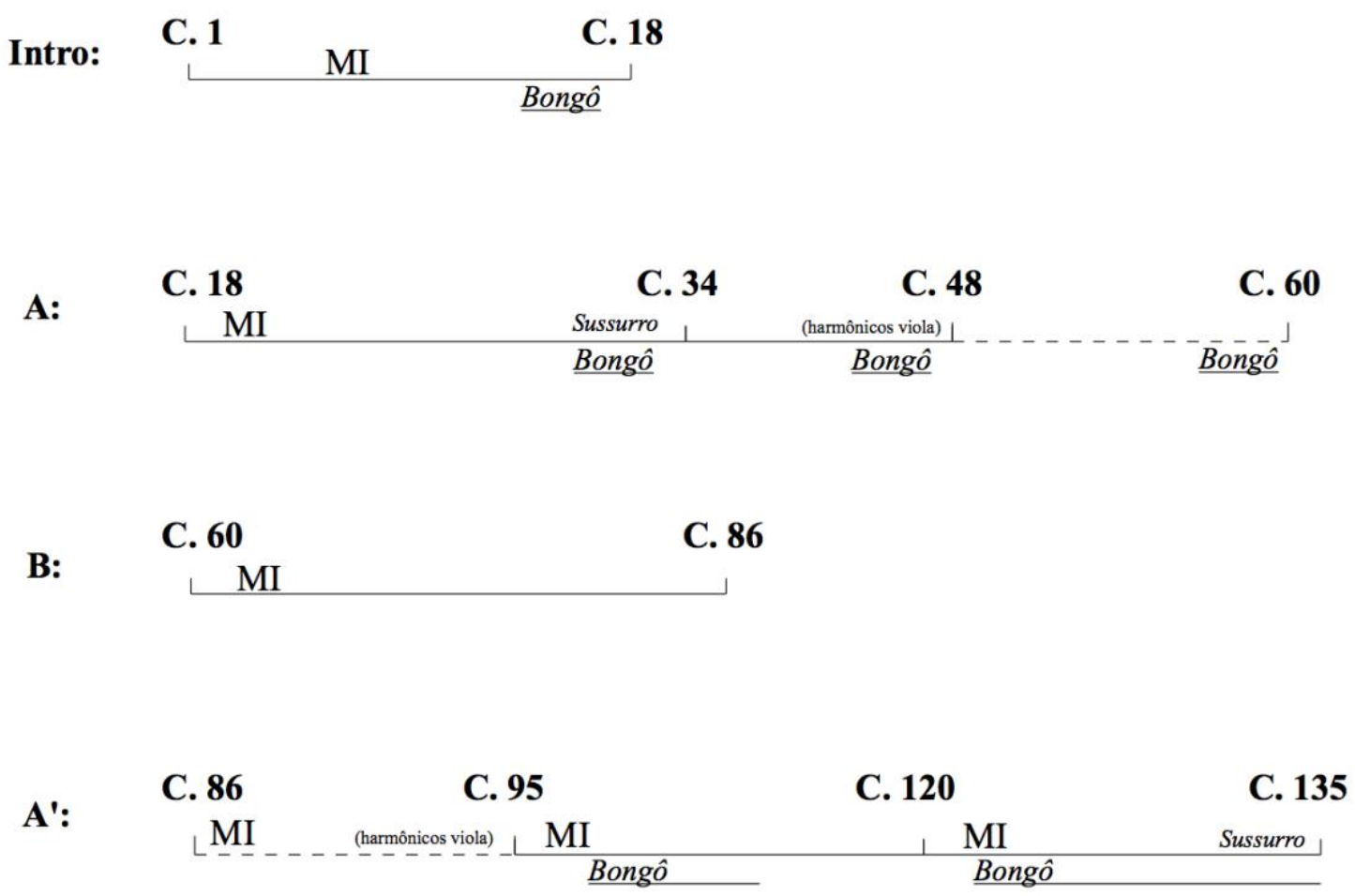

Figura 4 - Gráfico da estrutura global de $A$ Twilight's Song

\section{Motivos Delineadores}

A análise dos pontos articulatórios presentes nos compassos 18, 34, 48, 60, 86, 95, 120 e 135 será fundamental para melhor entender como ocorreu o processo de construção desta estrutura. Verifica-se que alguns motivos são sempre utilizados em locais específicos do discurso musical. Esse procedimento sugere funções específicas para essas entidades musicais, auxiliando na compreensão da forma pelos ouvintes. Pierre Boulez, ao analisar sua peça Sur Incises, no filme-documentário A Lesson by Pierre Boulez, de 1999, chama esse efeito de Reflexo de Pavlov. Segundo ele, esse processo leva o ouvinte a entender tais motivos como portadores de um significado. Sendo assim, se um motivo é utilizado para concluir uma seção, ao utiliza-lo novamente, o ouvinte eventualmente irá relaciona-lo com a chegada de um novo fim.

McAdams e Saariaho também discorrem sobre a importância da organização dos motivos musicais para a assimilação da forma: "A classificação de esquemas e sua organização devem, portanto, refletir possibilidades psicológicas ou essas estruturas não serão decodificadas pelo ouvinte e não contribuirão para a apreciação da forma musical" $(1985,367)$. Portanto, entende-se que a distribuição desses motivos no decorrer da obra influencia como os mesmos são percebidos, ajudando a salientar com mais eficácia o entendimento da estrutura global da peça. Devido a esta característica, esses motivos serão chamados de Delineadores Formais. O intervalo de terça maior baseado nas notas D-bemol - F é utilizado para iniciar seções e será chamado de Motivo Inicial (MI). As três grandes seções da peça iniciam sua melodia principal (figura $5 a, b, c)$ com esse intervalo. Além disso, conforme presente na figura 4, a segunda e terceira subseção de $A^{\prime}$ também são iniciadas com o MI. 


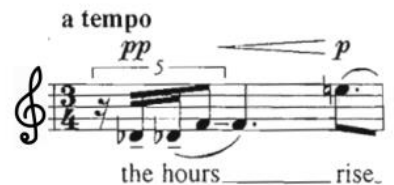

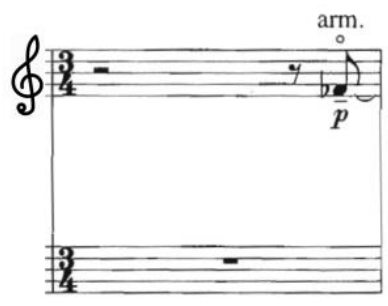

Figura 5a-C. 18 de $A$ Twilight's Song

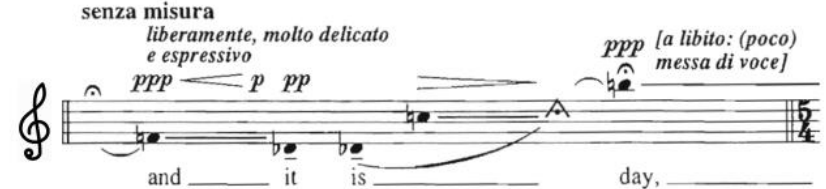

Figura 5b - C. 64 de $A$ Twilight's Song

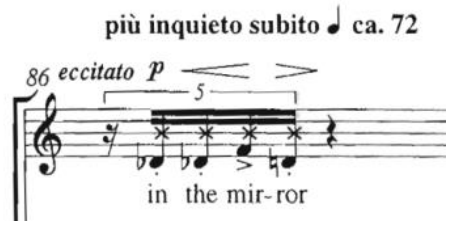

Figura 5c-C. 86 de A Twilight's Song

$\mathrm{Na}$ introdução, esse mesmo intervalo é utilizado para iniciar a melodia tocada pela flauta. Uma vez que a voz não aparece nesta seção, é a flauta que vai ocupar a posição de destaque melódico (figura 6).
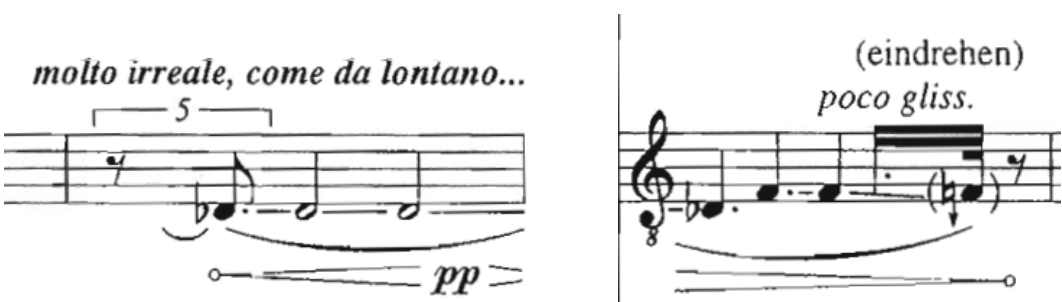

Figura 6 - C. 4-5 de A Twilight's Song

Outro motivo importante na peça é realizado no bongô. Esse motivo se destaca na obra devido ao seu timbre único e à sua recorrência apenas em fins de seções: fim da introdução (figura 7); fim das três subseções de $A$ (figura 4). Apesar de não aparecer na seção $B$, ele é retomado na seção $A^{\prime}$. Desta vez, ele se desenvolve desde o início até o fim das duas últimas subseções, marcando assim a chegada ao fim da obra.

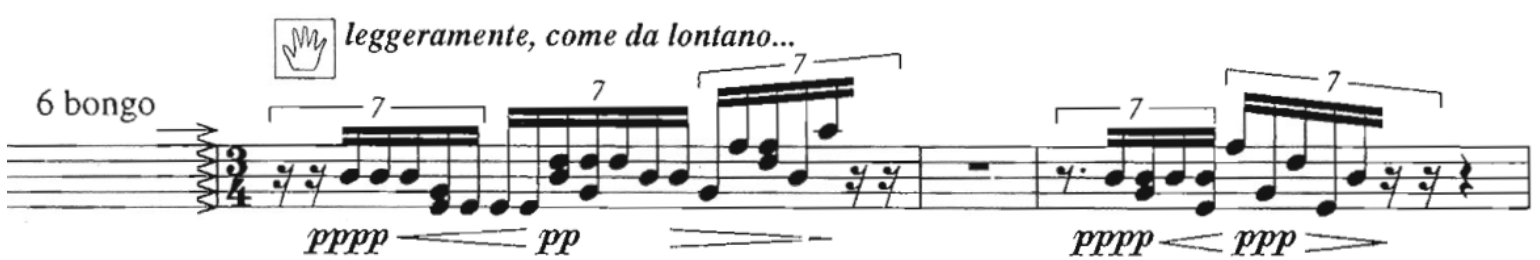

Figura 7 - C. 12-14 de A Twilight's Song

Além do motivo nos bongôs, mais dois motivos possuem a mesma função de terminação, aparecendo duas vezes na obra: A voz sussurrada (figura 8a) e o gesto em harmônicos da viola (figura 8b). 


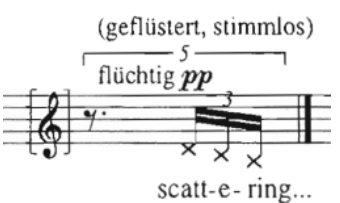

Figura 8a - C. 135 - Voz sussurrada

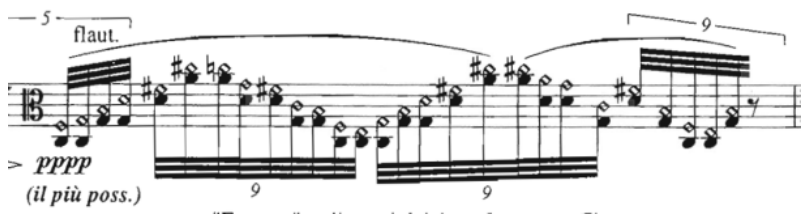

Figura 8b - C. 47 - Harmônicos na viola

A voz sussurrada tem a função de terminar a primeira subseção de $A$, bem como a própria obra, sendo essa finalização ressaltada pela associação entre as duas partes. O gesto em harmônicos na viola conclui a segunda subseção de $A$ e posteriormente a primeira subseção de $A^{\prime}$. Esse gesto torna-se especialmente interessante devido às suas características tímbricas, soando como se fosse oriundo de uma fonte sonora distante, reforçando a ideia de finalização. ${ }^{2}$ Lerdahl (1987) afirma que quando o timbre é organizado de forma hierárquica, o ouvinte torna-se capaz de inferir estruturas muito mais ricas. Em A Twilight's Song, o timbre tem um papel expressivo pois, associado à manipulação de texturas, torna-se determinante na compreensão da forma global da peça. Essas questões serão discutidas na seção 5 deste texto.

Pintscher ainda utiliza outra técnica para sugerir a aproximação do fim da peça. Sendo o texto um dos principais determinantes na manipulação motívica realizada por Pintscher, as frases "it is dawn", "it is day", "it is dusk" e "it is dark" apresentam semelhanças entre si (figura 9).

\section{23}

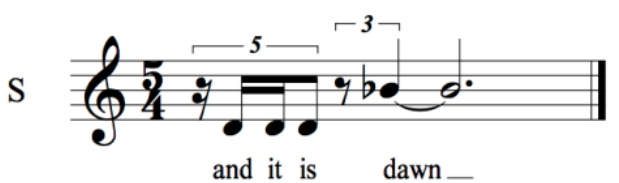

C. 104-105

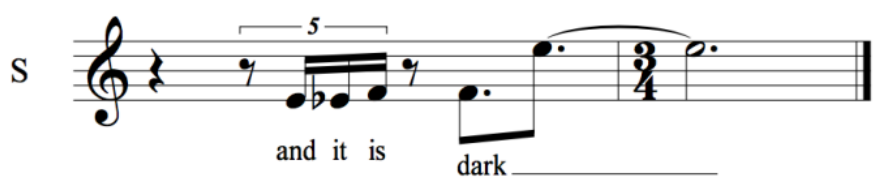

C. 46-47

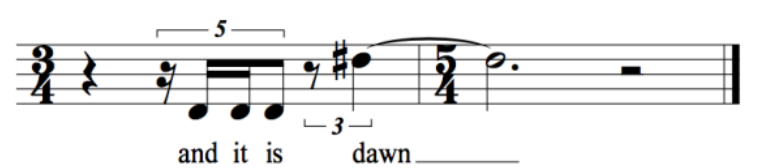

C. 64

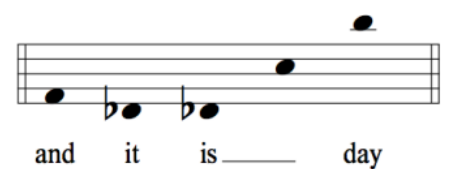

Figura 9- Todos os contornos melódicos da frase "it is".

Na primeira subseção de $A^{\prime}$, o material musical é instável, comparável com a terceira subseção de $A$, e soa semelhante a uma transição. Na chegada da segunda subseção de $A^{\prime}$ a peça retoma sua estabilidade, sendo assim, um ponto de destaque no desenvolvimento da obra. Nesse momento, a soprano canta "and it is dusk" (figura 10). O gesto musical realizado pela soprano nestes compassos é o único a ser interrompido entre as palavras "it" e "is". Este silêncio é preenchido por uma interferência instrumental.

${ }^{2}$ A utilização de timbres mais sutis para demarcar a terminação de frases musicais também pode ser encontrada no trabalho de outros compositores. João Pedro Oliveira, compositor português, utiliza esse mesmo procedimento na sua peça Titanium. O início da última seção da obra reutiliza os mesmos motivos rítmicos e harmônicos dos primeiros compassos, entretanto, alterados por técnicas estendidas como o damp e envoltos por uma atmosfera mais rarefeita. De acordo com o autor, esse tratamento é fundamental para a compreensão formal de Titanium, pois serve como um enunciado do fim da obra. 
Esta interrupção chama a atenção, pois quebra o padrão apresentado, surpreendendo as expectativas do ouvinte.

\section{95-97}

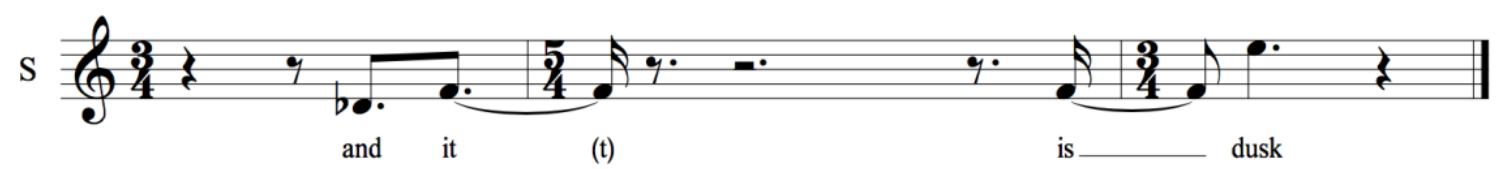

Figura 10 - C. 95-97 de A Twilight's Song

Tal interrupção prolongada e preenchida, não se trata apenas de mais uma variação. Ela possui importância estrutural, pois ocorre quando as ideias presentes em $A$ começam a ser reexpostas em $A^{\prime}$. Esse procedimento transmite aos ouvintes a sensação de diluição e rarefação de uma das principais melodias presentes na música, enfatizando que a tensão acumulada durante a peça já está sendo liberada, realçando a aproximação do fim da peça.

\section{Motivos Demarcadores}

Enquanto os Motivos Delineadores otimizam a compreensão dos pontos articulatórios ao longo da peça, em A Twilight's Song, existem também motivos que são utilizados para estabilizar o discurso musical, ajudando a demarcar algumas seções da música. Tal característica vai ao encontro do pensamento de Rossetti e Ferraz ao comparar a ideia de forma musical com as ideias de René Thom.

Para Thom (1990a: 183-184), a noção de forma sempre pressupõe a ideia de uma descontinuidade qualitativa topologicamente fechada (uma separação dos pontos do espaço contidos em uma forma daqueles que não estão contidos) que apresenta uma evolução temporal irreversível [...]. As saliências ou formas salientes seriam as descontinuidades perceptivas, os acidentes morfológicos [...]. As formas pregnantes ou pregnâncias estão ligadas à estabilidade de uma estrutura perceptiva $(2016,69)$.

Os Motivos Delineadores correspondem às formas salientes. Tais motivos são utilizados para destacar as descontinuidades no discurso musical, conduzindo a novas ideias. Após esses rompimentos, os Motivos Demarcadores (forma pregnante) são essenciais. Esses motivos aparecem apenas em seções específicas da peça, fornecendo uma identidade única para os trechos que são utilizados. Enquanto o mesmo Motivo Demarcador é utilizado, não ocorrem transições. Sendo assim, são fundamentais para a compreensão da estrutura musical, pois, ao mesmo tempo que são responsáveis pela reafirmação de uma ideia dentro de uma mesmo seção, auxiliam na criação de contraste entre diferentes seções da obra, fator essencial para que os ouvintes percebam tais articulações. Essa técnica cria um discurso que possui pontos de consolidação de uma ideia (Motivos Demarcadores) e, posteriormente, quebras (Motivos Delineadores), auxiliando o ouvinte na compreensão da forma global da obra. McAdams e Saariaho $(1987,367)$ também destacam a importância de ressaltar os pontos articulatórios na forma musical. Segundo os autores, nós nos lembramos mais facilmente de formas descontínuas do que formas contínuas, reforçando a validade desta técnica, pois auxilia o ouvinte a perceber as descontinuidades do discurso musical.

A análise da estrutura global de $A$ Twilight's Song contribui para a validação desse pensamento. Enquanto 
introdução e as seções $A$ e $A^{\prime}$ possuem características similares, a seção central (B) gera um intenso rompimento no discurso musical. Esse rompimento é essencial para delinear a estrutura global da obra, promovendo uma quebra drástica de expectativa no discurso musical, e criando tensão suficiente para que o clímax da peça ocorra em um dos momentos com menor movimentação e complexidade instrumental (chegada da seção B).

Dois Motivos Demarcadores se destacam ao longo de $A$ Twilight's Song. O primeiro ocorre entre os compassos 51-58 (figura 11), aparecendo de forma alternada entre o piano e harpa. O segundo aparece pela primeira vez entre os compassos 34-38 (figura 12).

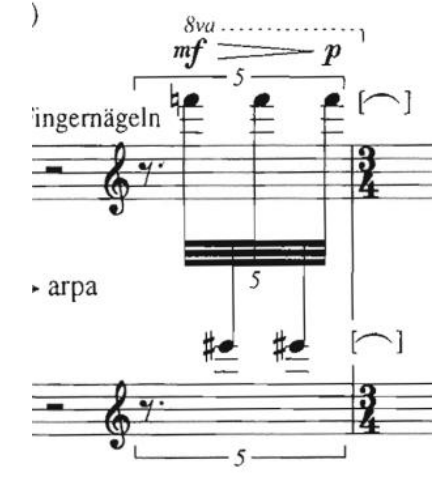

Figura 11 - C. 51 de $A$ Twilight's Song.

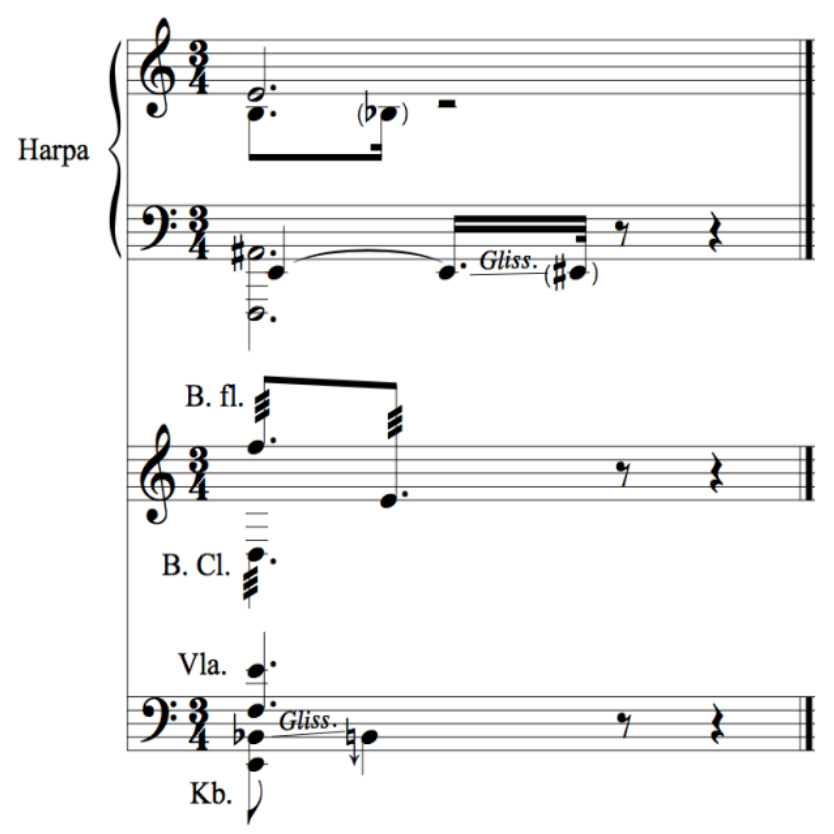

Figura 12 - Motivo presente no compasso 34 de A Twilight's Song.

Localizando-os no gráfico estrutural de $A$ Twilight's Song (figura 4), pode-se perceber que ambos aparecem apenas em âmbitos de subseções específicas da seção A. Eles relacionam-se com outras ideias musicais presentes na obra, entretanto, devido ao processo de variação utilizado para cria-los assim como as respetivas orquestrações e tessituras (o primeiro no extremo agudo e o segundo no extremo grave), ambos se destacam no contexto em que são utilizados, atraindo a atenção do ouvinte. Esse procedimento facilita sua memorização e a memória é um fator essencial no reconhecimento da forma musical. Segundo os McAdams e Saariaho (1987, 367), "se algum elemento é facilmente relembrado, seu potencial de 
contribuição para a forma é maior que de outro elemento difícil de ser lembrado". Assim, esses motivos proporcionam uma identidade própria a essas subseções.

A função desses motivos se torna ainda mais clara quando o segundo Motivo Demarcador (figura 12) retorna na música (compassos 104-108), demarcando, também, a segunda subseção de A’. Como já afirmado, o poema de e. e. cummings possui uma forma cíclica, sendo assim, possui trechos que se repetem durante seu desenvolvimento. Quando o Motivo Demarcador é retomado, a frase cantada pela soprano é similar a usada na seção em que esse motivo foi inicialmente apresentado. Durante a sua primeira aparição, segunda subseção de A, a soprano cantava "the city wakes, with a song upon her mouth having death in her eyes". Em sua segunda aparição, "the city sleeps, with death upon her mouth having a song in her eyes". Desta forma, como já havia sido discutido, Matthias Pintscher utiliza a linha melódica realizada pela soprano para ressaltar a diferença de significado presente no texto, entretanto, utiliza o grupo instrumental para reforçar a semelhança existente entre o conteúdo linguístico dessas seções. Sendo assim, a segunda subseção de A e A' carregam entre si semelhanças textuais e a manipulação dos procedimentos musicais reforçam a identidade presente entre esses momentos.

Embora os motivos acima expostos sejam de grande relevância para a estruturação de $A$ Twilight's Song, outros parâmetros musicais (dentre os quais destacamos a densidade textural) também ajudam a reforçar as articulações entre as suas seções. O compositor associa a manipulação desse parâmetro com uma delicada exploração tímbrica que enfatiza a percepção do desenvolvimento das ideias musicais. Essas questões serão abordadas na próxima seção.

\section{Textura e exploração tímbrica}

Ao longo da história da música ocidental foram desenvolvidos quatro tipos de texturas musicais: monofônica, polifônica, homofônica e heterofônica. Segundo Strizich (1991, 1), com a revolução ocorrida na linguagem musical durante o século $X X$, essa terminologia tornou-se obsoleta, não sendo mais adequada para explicar todos os processos texturais utilizados pelos compositores:

Na minha opinião, nossos conceitos tradicionais, definições e termos são inadequados para a discussão e análise das novas texturas na música do pós-Segunda Guerra Mundial. De fato, boa parte da música desde 1945 vai bem além do alcance da terminologia analítica padrão, principalmente porque muitos desses trabalhos fazem uso exclusivo de texturas e procedimentos texturais que se distanciam significativamente das práticas convencionais. A literatura atual sobre música contemporânea também não auxilia muito nesse assunto. $\mathrm{Na}$ verdade, o tópico 'textura' tem sido geralmente tratado superficialmente (se tratado) em artigos, periódicos e livros sobre a música nova. Portanto, se tem uma necessidade por uma investigação sobre esse tópico que levaria em consideração diversos assuntos: 1) uma definição de textura que seria ampla suficiente para cobrir o fenômeno textural atual; 2) uma análise detalhada desses novos tipos básicos de textura; 3) o desenvolvimento de uma terminologia adequada para eles; 4) uma consideração de como essas novas texturas foram empregadas no contexto composicional como um todo $(2001,1)$ 
Segundo Panayiotis Kokoras, no pós-guerra, consolidou-se mais um tipo de textura musical, a textura holofônica (figura 13), sendo "melhor percebida como a síntese de uma corrente de sons simultâneos que geram um todo coerente com componentes internos e pontos de foco" $(2005,2)$. Esse procedimento textural é frequentemente utilizado em A Twilight's Song.

\begin{tabular}{|c|c|c|}
\hline Period & Graphic representation & $\begin{array}{l}\text { Type of } \\
\text { Texture }\end{array}$ \\
\hline $400-1450$ & & $\begin{array}{c}\text { Monophonic } \\
\text { Texture }\end{array}$ \\
\hline $1450-1750$ & & $\begin{array}{l}\text { Polyphonic } \\
\text { Texture }\end{array}$ \\
\hline $1750-1950$ & & $\begin{array}{c}\text { Homophonic } \\
\text { Texture }\end{array}$ \\
\hline 1950- & & $\begin{array}{c}\text { Holophonic } \\
\text { Texture }\end{array}$ \\
\hline
\end{tabular}

Figura 13 - Representação gráfica realizada por Kokoras (2005) para exemplificar os diversos tipos de texturas.

Pintscher estabelece uma alternância entre textura heterofônica e holofônica, criando tensão e fortalecendo seu processo articulatório. Devido às características intrínsecas a esses dois tipos de textura ${ }^{3}$, o compositor desenvolve a ideia de movimento em sua obra, alternando entre momentos de menor e maior tensão. Desde a primeira entrada da soprano (figura 14), o corpo instrumental que a acompanha ressoa algumas das notas que foram cantadas. No exemplo, a harpa ressoa o mi bequadro; o piano, o fá sustenido; e as cordas, o fá bequadro. Este tratamento continua sendo desenvolvido e sua complexidade gradualmente intensificada. Ao se aproximar dos pontos de articulação, a complexidade já é tão grande que o ouvinte pode escutar apenas uma complexa corrente sonora. Nestes momentos de maior complexidade, a textura torna-se holofônica. Nos compassos 57-59 (figura 15), a peça caminha para seu clímax, concluindo sua primeira seção. O contraponto entre os instrumentos é intrincado e o ouvinte escuta apenas uma massa sonora com alguns pontos de apoio, onde os gestos musicais mais ricos em harmônicos, como os glissandi na percussão (fim do compasso 57) ou a técnica de overblow no clarone (fim do compasso 58) ganham destaque na escuta. A textura holofônica também é utilizada de forma mais presente nos compassos 15-17, 29-33, 47 e 86-94 $4^{4}$. Como se pode observar no gráfico estrutural da peça (figura 4), todos esses momentos refletem articulações estruturais.

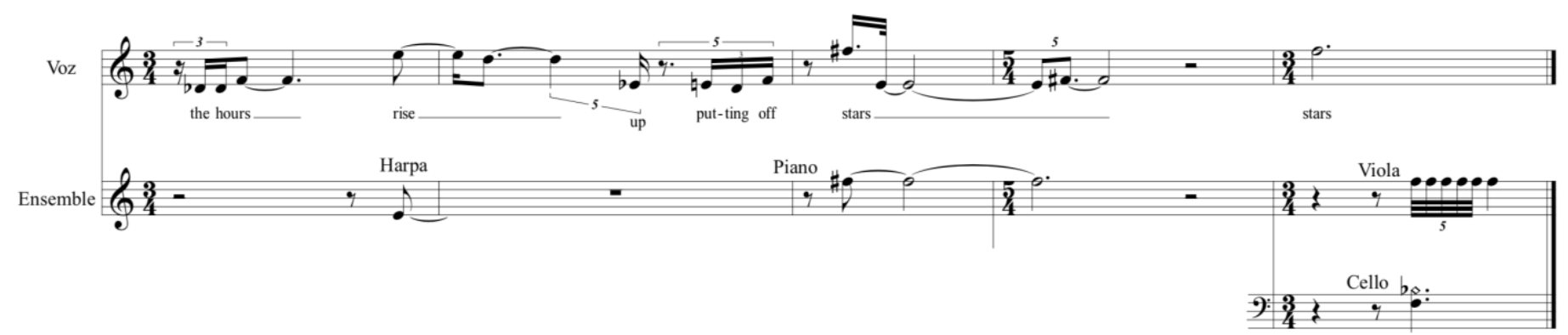

Figura 14 - C. 18-22 - Ensemble ressoando notas da soprano

${ }^{3}$ A textura holofônica é por definição mais densa que a textura heterofônica.

${ }^{4}$ A textura holôfonica também é utilizada de forma menos densa em outros momentos da obra. 
Portanto, Matthias Pintscher emprega diferentes texturas para enfatizar os pontos articulatórios da peça. Como a textura holofônica possui, por definição, um maior número de gestos musicais, ela é mais densa, auxiliando na condução a novas ideias. Esse procedimento se baseia na manipulação da relação tensãorelaxamento. A importância do estabelecimento desse controle é destacada por diversos autores. João Pedro Oliveira (2010) afirma:

A compreensão deste fenômeno (tensão-relaxamento), e a descoberta de caminhos para a sua aplicação na prática, será talvez, o objetivo mais importante a atingir. Todas as relações atrás abordadas (relação monodia-harmonia, polifonia-harmonia, verticalidadehorizontalidade e limite entre polifonia e textura sonora), deverão orientar-se na direção do estabelecimento de procedimentos individuais, que possam dar resposta às necessidades específicas de cada composição, quer no contexto da frase isolada, quer na concepção das obras $(2010,22)$.

McAdams também discorre sobre o assunto. De acordo com o autor (McAdams 1999, 96), esse senso de movimento entre tensão e relaxamento é considerado por muitos teóricos como um dos suportes principais para a percepção de forma musical em larga escala. Matthias Pintscher se faz valer desse princípio, moldando a estrutura global de sua obra a partir da manipulação dessas relações. Em $A$ Twilight's Song, os pontos de maior tensão são enfatizados também por sua estruturação tímbrica. De acordo com Cohen e Dubnov, "Textura [...] pode ser vista como um super parâmetro que se relaciona com a combinação de diversos outros parâmetros" (1997, 387). Para Strizich $(1991,1)$, ao realizar uma análise textural deve-se levar em consideração a manipulação vertical e horizontal dos eventos musicais, sendo o termo vertical relativo à densidade textural e o horizontal às inter-relações produzidas por sons sucessivos, sendo tais parâmetros frequentemente "manipulados para contribuir a um processo global ou um gesto expressivo". Ainda segundo o autor:

Transformação permite um compositor a mudar gradativamente de uma condição textural a outra, criando um efeito de transição, evolução, ou (novamente) aumento/diminuição de tensão. Transformação é alcançada pela alteração proposital e direcional de qualquer aspecto básico de uma textura. Timbre, densidade, ritmo, dinâmica, tipo de material ou articulação são apenas alguns dos parâmetros que podem ser modificados $(1991,14)$.

Como já discutido, a manipulação de densidade vertical foi um dos principais aspectos utilizados por Matthias Pintscher para intensificar a sensação de movimento na sua peça e, assim, ressaltar os pontos articulatórios de $A$ Twilight's Song. Esta complexificação textural é acompanhada pela exploração tímbrica (parâmetro horizontal), utilizada para enfatizar as relações sugeridas pela manipulação vertical. Os inícios de seções são, primariamente, constituídos por sons harmônicos (com alturas bem definidas). Como pode se ver na figura 5a (inicio da primeira seção), a soprano é acompanhada apenas pelo dobramento da mesma nota na harpa. Na sequência, sons inarmônicos e ruidosos vão sendo acrescentados e o ápice de uso destes sons ocorrem nos pontos de maior complexidade textural. No fim da primeira seção (figura 15), técnicas ruidosas como pizzicato bartok, col legno e pressão de arco são utilizadas nos instrumentos de cordas, slap ou overblow são utilizados nos sopros e, na percussão, com exceção de um único gesto que utiliza instrumento com altura definida (crotales), apenas instrumentos inarmônicos são utilizados. 
Deixando claro como Pintscher associa as suas estruturas tímbricas às suas estruturas texturais, otimizando as articulações da obra.

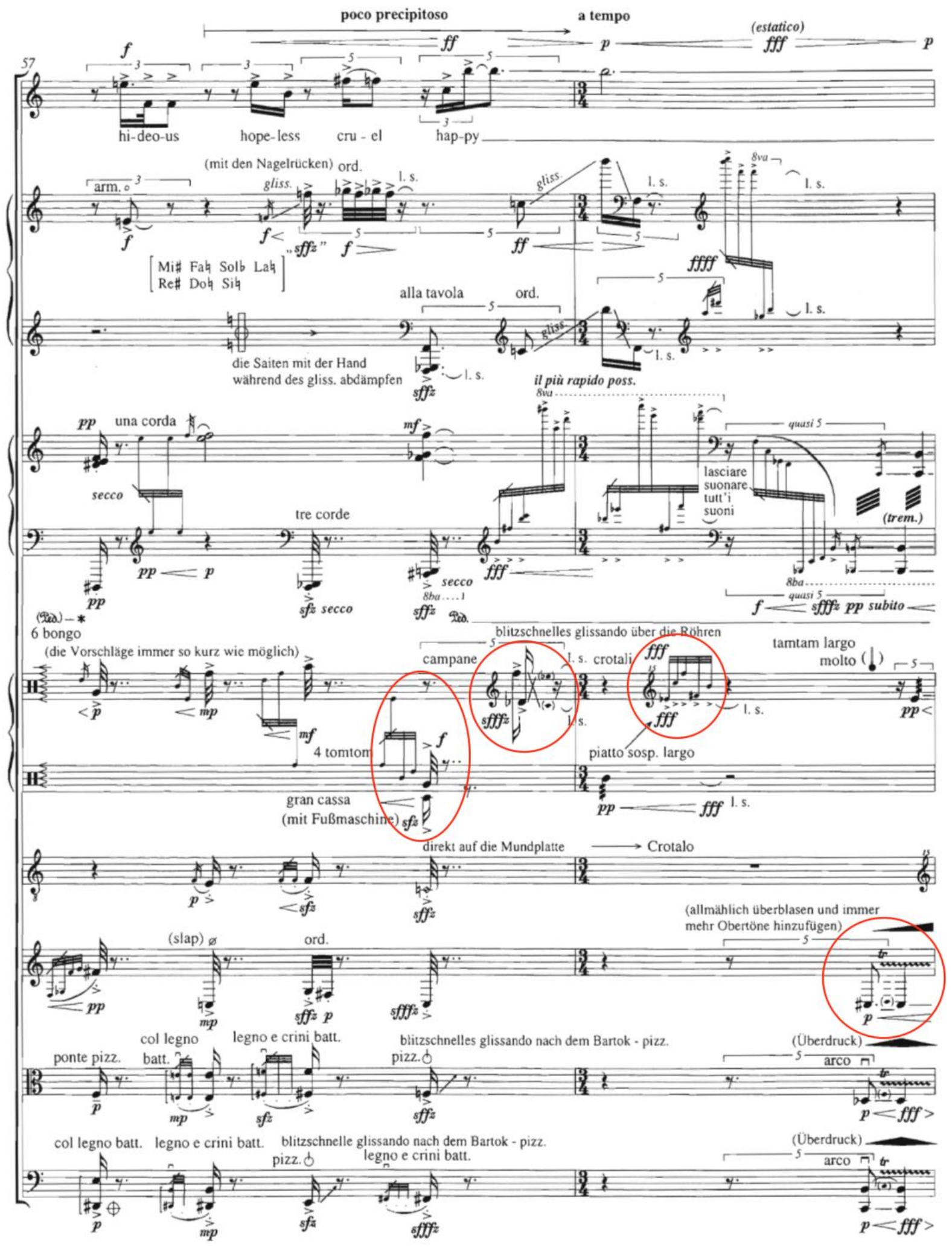

Figura 15 - C. 57-58 de A twilight's song

Segundo McAdams $(1999,96)$, estudos no campo da harmonia sugerem que aspereza auditiva (auditory roughness) é um atributo tímbrico importante para a percepção de tensão musical, por isso, frequências muito próximas, que geram batimentos, tendem a ser assimiladas pelo ouvinte como mais dissonantes. Tal principio pode ser estendido também ao campo do timbre. De acordo com Marecos (2011), 
É também esta gama intermédia, de alguma imprecisão, que importa explorar, conferindo à música e à sua sonoridade diferentes qualidades acústicas, podendo ligar a inarmonicidade a uma maior friç̧ão, a uma maior tensão, algo próximo do conceito de 'dissonância', e a harmonicidade associar à estabilidade, a uma maior fusão, aos conceitos de relaxamento, de repouso, ou, pensando de uma forma mais comum, ligá-la ao conceito de 'consonância'. A gama intermédia pode ser, assim, um vasto território a explorar na dicotomia entre a estabilidade e a instabilidade, assumindo-se também as transições entre ambos os conceitos como elemento definidor do discurso, que contribui para a sucessão harmónica, essencial no próprio processo de composição $(2011,71)$.

A associação dos sons harmônicos e inarmônicos aos conceitos de consonância e dissonância, como exposto por Marecos e similar à exploração tímbrica realizada por Pintscher em A Twilight's Song, também é usado por Kaija Saariaho na concepção de sua peça Im Traume (1980) onde "equilíbrio (stasis) é representado pelo uso de técnicas instrumentais tradicionais, enquanto técnicas estendidas introduzem tensão" (Saariaho 1987, 104). Tal técnica é comum no pensamento musical de Saariaho. Segundo ela,

Em minha música, eu tenho uma tendência a relacionar o controle de timbre com o controle de harmonia. Inicialmente, eu comecei a usar o eixo som/ruído para desenvolver frases musicais e grandes formas e, assim, criar tensões na música. No sentido abstrato e atonal, o eixo som/ruído pode ser um substituto da noção de dissonância/consonância. Uma textura áspera e barulhenta seria assim o paralelo à dissonância, enquanto que uma textura suave e limpa corresponde a consonância. É verdade que o ruído é, no sentido puramente físico, uma forma de dissonância levada ao extremo $(1987,94)$.

Para Saariaho (1987, 94), "Quando o timbre é utilizado para criar forma musical é, precisamente, o timbre que toma o espaço da harmonia como elemento de progressão em música". Quando Pintscher varia o timbre dos sons harmônicos até alcançar os sons ruidosos, sua intenção é precisamente criar progressão na música, desta forma, pode-se afirmar que, em A twilight's song, por muitas vezes, o timbre toma o espaço da harmonia como elemento de progressão. Esta técnica de progressão musical é ressaltada por Saariaho:

Eu fiquei profundamente interessada no fenômeno de transição e sua realização através de diferentes parâmetros. Um sistema de modulação na música tonal pode ser o exemplo de uma transição musical dinâmica que cria senso de movimento. A música é então caracterizada por um poderoso senso de movimento que pode ser reforçado ainda mais pelo uso de outros parâmetros $(1987,104)$.

Em A Twilight's Song, como proposto por Kaija Saariaho, as combinações de diferentes parâmetros musicais enfatizam as estruturas globais da obra. Esses parâmetros são manipulados de maneira coerente, tendo suas funções reforçadas pelos demais. A manipulação tímbrica auxilia o aumento de tensão presente na transformação das texturas musicais. A relevância dessas combinações também é ressaltada por Rosetti (2016):

A superposição e a justaposição de texturas e estruturas diferentes resultam na criação da forma. Dentro de uma análise formal podem-se distinguir diferentes estados de 
agregação dos materiais musicais, estados estes que articulam diferenças de timbre e de densidade, relacionados aos diferentes tipos de materiais utilizados. A combinação entre os diferentes tipos de materiais, assim como a articulação da transição temporal gradual entre eles constitui o esqueleto da forma $(2016,79)$.

\section{Manipulação motívica e harmônica na seção B}

Como já afirmado anteriormente, a seção B representa um amplo rompimento no discurso musical. Devido ao seu forte contraste com as demais seções da obra, possuindo diferenças quanto à densidade, timbre e velocidade de desenvolvimento dos motivos musicais, decidimos realizar sua análise separadamente. Vale relembrar que essa seção funciona como eixo de espelhamento formal da peça, ou seja, possui uma função estrutural importante, explicando o motivo de ser tão contrastante. Tal qual o poema de e. e. cummings (figura 1), a única frase cantada ao longo da seção central é a frase "and it is day".

Apesar de todo o contraste, ainda encontramos na seção B semelhanças harmônicas e temáticas com o restante da obra. Durante essa seção, o compositor pede que o flautista, harpista e percussionista toquem crotales $^{5}$, gerando uma atmosfera musical timbricamente muito homogênea. Com a estabilização do timbre, a harmonia retoma seu papel tradicional de criar progressão em música, diferindo também nesse aspecto das outras seções ${ }^{6}$.

A Twilight's Song possui sua harmonia baseada majoritariamente em graus conjuntos que são preenchidos cromaticamente em diversos momentos da peça: na figura 2, ambas as melodias são baseadas no preenchimento cromático do intervalo mi bemol-fá natural; na figura 3, entre os compassos 18-21, o preenchimento cromático vai de ré bemol até fá sustenido e, nos compassos 120-123, existem dois preenchimentos cromáticos, de si bequadro a dó sustenido e de mi bequadro a fá sustenido.

A harmonia utilizada nos compassos 120-123 é exatamente a mesma utilizada na seção B. Matthias Pintscher utiliza o si bequadro como nota pedal, estando presente em todos os compassos da seção $B$. As notas restantes são utilizadas para criar tensão e relaxamento. Mi e Fá sustenido, quinta justa abaixo e acima (intervalos consonantes), criam repouso e dó, dó sustenido e fá - segunda menor, segunda maior e quinta diminuta (intervalos dissonantes) pretendem gerar tensão. A figura 16 apresenta uma redução harmônica dos compassos 60-63 e 65-78 da seção B.

Nos compassos 60-63, a harmonia é quase inteiramente baseada no si bequadro. Além desta nota, Pintscher também utiliza dó bequadro. A tensão gerada por esse intervalo de semitom, é resolvida no fim, quando a harmonia volta unicamente ao si bequadro. O mesmo processo é realizado com maior complexidade nos compassos 65-78. A harmonia inicia-se novamente com um único si bequadro, a partir do qual são adicionadas várias dissonâncias, que são posteriormente resolvidas: nos compassos 65-66, aparecem dó bequadro e dó sustenido que são resolvidos, voltando novamente ao si bequadro no c. 69; nos compassos 69-70, a dissonância si bequadro - dó bequadro é novamente utilizada, resolvendo no compasso 71; no compasso 73 encontra-se uma resolução clássica da harmonia tonal, com uma quinta

5 O harpista alterna entre harpa e crotales e o percussionista entre vibrafone e crotales. O flautista toca apenas crotales. Todos os crotales (e o vibrafone) são tocados com arco.

${ }^{6}$ Nas demais seções da obra, a harmonia é estática, sendo o timbre e textura responsáveis por criarem a ideia de progressão. 
diminuta resolvendo descendo um semitom abaixo. Apesar de não usar um pensamento tradicional, podese afirmar que o procedimento realizado por Matthias Pintscher para criar tensão-relaxamento harmônico na seção B desta obra é intimamente conectado com as leis da harmonia tonal. Enquanto que nas seções anteriores essa alternância era criada pela exploração tímbrica e pela densidade textural, nesta seção os intervalos dissonantes resolvem em intervalos consonantes, numa relação que se aproxima do $V^{7}-I$ da tonalidade clássica.

C. 60-63

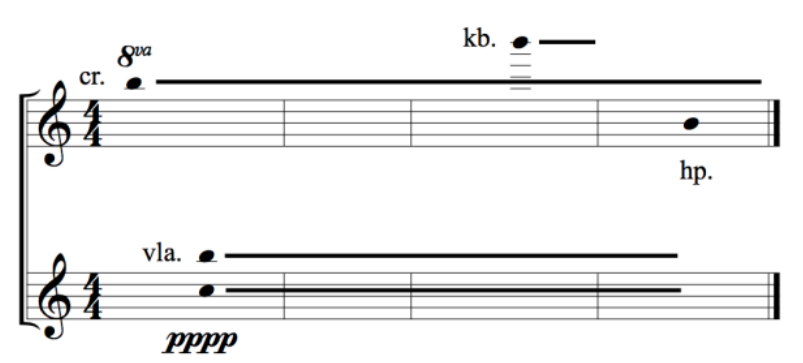

C. 65-78

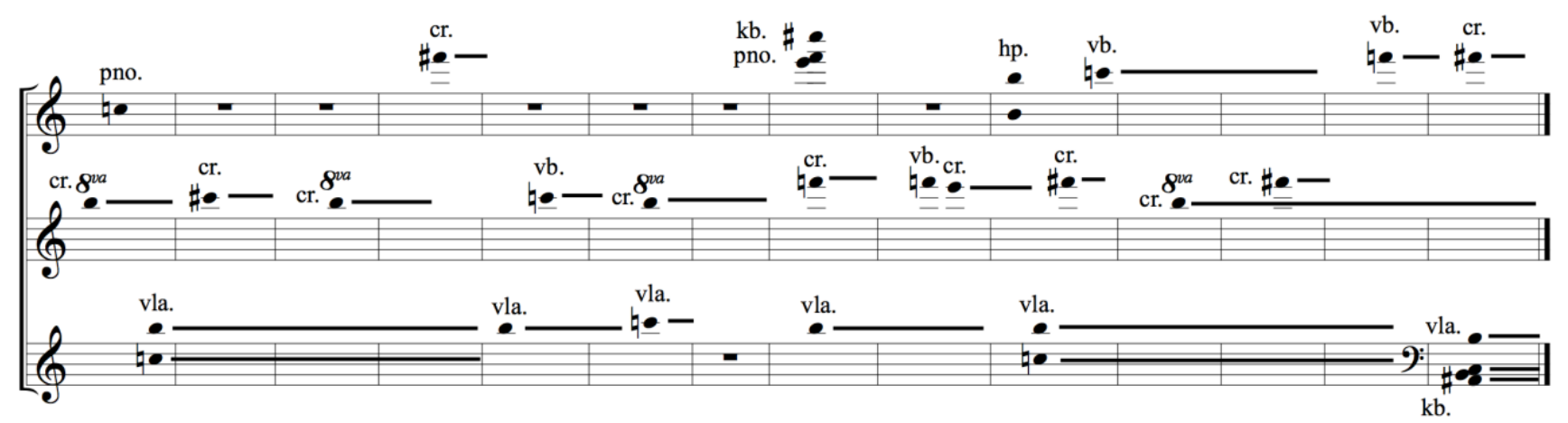

Figura 16 - Redução harmônica da seção B de A Twilight's Song.

Além das semelhanças harmônicas, a melodia baseada no Motivo Inicial (MI) (Figura 5a, b e c) também é retomada na seção B. No c. 64 (figura 5b), o intervalo de terça maior é mais uma vez utilizado, mantendo o mesmo padrão melódico inicial de todas as seções da peça. Ainda mais, apesar de não ter ritmo especificado, o padrão melódico que aparece em todos "and it is" também é mantido (figura 9).

Na seção $B$, a orquestração, que nas primeiras seções se encontrava no registro médio-grave, é levada para o extremo agudo. Esta opção demonstra, novamente, a influência do texto nas escolhas composicionais de Matthias Pintscher. Quando o poema narra o amanhecer na cidade "and it is day", a música acompanha essa ideia, sendo levada ao registro mais brilhante. Essa opção pelo novo registro cria um forte contraste com as ideias musicais utilizadas antes e depois dessa passagem, fator decisivo para o estabelecimento da seção B. Sendo assim, a frase anunciando o nascer do dia (“...and it is day...") retrata não só uma articulação importante na descrição imagética realizada no poema de e. e. cummings, mas também aparece como uma importante articulação na estrutura musical. 


\section{Conclusão}

Nessa análise, buscamos elucidar alguns aspectos relevantes na construção formal de $A$ Twilight's Song. Como pode ser visto, a estruturação realizada por e. e. cummings no seu poema The Hours Rise Up Putting Off Stars traz fortes reflexos à organização formal da peça, onde os ciclos de repetição do texto são representados musicalmente. Desta maneira, tal qual o poema, a peça possui uma estrutura espelhada na qual a frase "and it is day" é o eixo central.

Matthias Pintscher se dispõe de diversos recursos motívicos, harmônicos, tímbricos e texturais para ressaltar os pontos de articulação formal da obra. Por muitas vezes, esses recursos são combinados e utilizados em conjunto para exacerbar ainda mais as intenções formais do compositor para os ouvintes. Acreditamos que este estudo apresenta questões importantes que podem ser utilizadas como base para estudos analíticos de outras obras de Matthias Pintscher, como também, de outros compositores.

O dialogismo existente no pensamento composicional torna-se notório ao comparar as técnicas analisadas em A Twilight's Song com a bibliografia de referência. Esse aspecto é de grande interesse para a pesquisa. Segundo Pierre Boulez:

Malraux falava que para se tornar um pintor, deve-se olhar para pinturas, não para paisagens. Você se torna um músico porque você estuda música e os compositores que precederam você e, a partir disso, deduz certas coisas. Lembrando que deduzir não significa copiar. Realmente, significa deduzir [...], ver as consequências do que os outros já fizeram. (BOULEZ, Pierre. Juxtapositions: Boulez Éclat - Sur Incises. [2000]. França: A lesson by Pierre Boulez. Entrevista concedida a Andy Sommer.)

Sendo assim, espera-se que as técnicas composicionais aqui analisadas sejam úteis para uma maior compreensão do pensamento musical de Matthias Pintscher e que, como sugerido por Boulez, os resultados encontrados sejam deduzidos e reutilizados em novas obras, auxiliando os compositores a se manterem atualizados, contribuindo, assim, para o desenvolvimento da linguagem musical.

\section{Referências}

Cohen, Dalia e Dubnov, Shlomo. 1997. "Gestalt phenomena in musical texture". In: Leman, Marc (Org.). Music, Gestalt and Computing: Studies in Cognitive and Systematic Musicology. Berlin: Springer-Verlag Berlin Heidelberg.

Kokoras, Panayiotis. 2007. "Towards a Holophonic Musical Texture". Journal of Music and Meaning (JMM), (Dinamarca: University of Southern Denmark), v. 4, n. 5: 1-3.

Lerdahl, Fred. 1987. "Timbral Hierarchies". Contemporary Music Review (Reino Unido: Harwood Academic Publishers GmbH), v.2: 135-160.

Marecos, Carlos. 2011. "Interacção entre estruturas intervalares e estruturas espectrais, na música instrumental/vocal". Tese de doutorado, Aveiro: Universidade de Aveiro.

McAdams, Stephen; Saariaho, Kaija. 1985. "Qualities and functions of musical timbre". In International Computer Music Conference (Canadá: Simon Frasier University): 367-374. 
McAdams, Stephen. 1999. "Perspectives on the Contribution of Timbre to Musical Structure". Computer Music Journal, n.3, v.23: 85-102.

Oliveira, Levy; Oliveira, João Pedro. 2018. "Procedimentos estruturais na obra Titanium de João Pedro Oliveira". Música Hodie, n.1, v.17: 71-98.

Oliveira, João Pedro. 2010. Sistema, Intuição e Tempo: Por uma identidade composicional. Texto não publicado.

Oliveira, João Pedro. 2014. Titanium. França: Babel Scores. Partitura.

Pintscher, Matthias. 1997. A twilight's song. Kassel: Bärenreiter. Partitura.

Rossetti, Danilo; Ferraz, Silvio. 2016. "Forma musical como um processo: do isomorfismo ao heteromorfismo". Opus, [s.I.], v. 22, n. 1: 59-96.

Saariaho, Kaija. 1980. Im Traume. Hämeenlinna, Finland: Jasemusiikki. Partitura.

Saariaho, Kaija. 1987. "Timbre and Harmony: Interpolations of timbral structures". Contemporary Music Review (Reino Unido: Harwood Academic Publishers GmbH), v. 2: 93-133.

Sommer, Andy. 2000. A lesson by Pierre Boulez. [Filme-vídeo]. Direção de Andy Sommer. DVD, 49min. França: EuroArts.

Strizich, Robert. 1991. "Texture in Post-World War II Music". Ex Tempore. n.2, v.5, p. 1-21. www.extempore.org/strizich91/strizich.htm 